\title{
Effects of Heat Treatment on Fatigue Strength of Occlusal Rests Cast with Ag-Pd-Cu-Au Alloy
}

Yorio Hayashi, RDT, ${ }^{a}$ Hiroshi Kobayashi, DDS, PhD, ${ }^{b}$ Yoshiaki Yamada, DDS, PhD, ${ }^{c}$ Osamu Miyakawa, BE, PhD, ${ }^{d}$ and Kazuo Tsujimoto, DE, PhDa

${ }^{a}$ School of Materials Science, Biological Science and Biotechnology, Japan Advanced Institute of Science and Technology (JAIST), Noumi, Japan

${ }^{\mathrm{b}}$ Division of Removable Prosthodontics, Niigata University Graduate School of Medical and Dental Sciences, Niigata, Japan

${ }^{c}$ Division of Oral Physiology, Niigata University Graduate School of Medical and Dental Sciences, Niigata, Japan

dDivision of Biomaterial Science, Niigata University Graduate School of Medical and Dental Sciences, Niigata, Japan

\section{Clinical significance}

The breakage of essential structures determines the life of a removable partial denture. The occlusal rest is an important part of denture that provides support against the occlusal forces. Three types of heat treatment were investigated with the aim of improving the fatigue strength of occlusal rests cast with an $\mathrm{Ag}-\mathrm{Pd}-$ $\mathrm{Cu}$ alloy containing $12 \mathrm{wt} \% \mathrm{Au}$.

\begin{abstract}
Purpose: To avoid early fatigue fracture of occlusal rests, the optimum heat treatment condition was sought.

Methods: Each specimen consisted of an occlusal rest (thickness, $0.8 \mathrm{~mm}$ ), vertical minor connector, and denture base connector. The specimens were conventionally cast, steam cleaned, and finally pickled in a cleaning solution. The heat treatment conditions were classified as as-cast, manufacturer's instruction, and $800^{\circ} \mathrm{C}$ solution treatment. Twenty-six specimens were prepared for each of the 3 groups.

A fatigue testing machine was designed so that the occlusal rest component could be deflected by displacing the denture base connector downward. A displacement of $0.46 \mathrm{~mm}$ was predetermined from the loaddeflection relationship of the specimens. Cyclic load was applied at a frequency of 500 cycles/min until occlusal rest failures occurred or the preset limit of 2 million cycles was reached. Subsequently, Rockwell hardness was tested on the base surface. The results were statistically analyzed.
\end{abstract}

Corresponding to: Dr Hiroshi Kobayashi

Removable Prosthodontics, Graduate School of Medical and Dental Sciences, Niigata University,

2-5274 Gakkocho-dori, Niigata 951-8514, Japan

Tel: +81-25-227-2890, Fax: +81-25-229-3454

E-mail:kobayash@dent.niigata-u.ac.jp

Received on June 6, 2006 / Accepted on August 31, 2006
Results: All the specimens fractured within the preset limit. The heat treatments significantly influenced the fatigue resistance $(P<0.003)$. A significant difference $(P<0.05)$ was detected between the $800^{\circ} \mathrm{C}$ solution treatment and manufacturer's instruction groups. The heat treatments significantly influenced the hardness $(P<0.001)$. A significant difference $(P<0.05)$ was observed between the as-cast and manufacturer's instruction groups and between the $800^{\circ} \mathrm{C}$ solution treatment and manufacturer's instruction groups.

Conclusion: The $800^{\circ} \mathrm{C}$ solution treatment was most favorable for the improvement of fatigue resistance. The heat treatment based on the manufacture's instruction increased mostly the hardness; however, it was unsuitable for improving the fatigue resistance.

Key words: fatigue, $\mathrm{Ag}-\mathrm{Pd}-\mathrm{Cu}-\mathrm{Au}$ alloy, heat treatment, occlusal rest

\section{Introduction}

Mechanical failures in removable partial denture (RPD) frameworks usually occur not immediately but after years of service. ${ }^{1,2}$ Previous reports indicate that the components of the frameworks undergo fatigue. This implies that a particular material or structure eventually fails after being subjected to repeated small stresses, and that the frameworks will not fail when subjected to a single load.

Several studies have shown that normal mastication can produce thousands of stress cycles per day. ${ }^{3,4}$ Thus, fatigue resistance is an important factor for the clinical durability of dental materials such as those used in restorations, prostheses and so on. Among the RPD components, greater attention has been given to studies on the fatigue 
behavior of clasp arms. ${ }^{5-7}$ Ben-Ur et al $^{8}$ studied the rigidity of major connectors subjected to bending and torsion forces, whereas Ohkubo et $\mathrm{al}^{9}$ compared the fatigue strengths of different designs of denture bases for RPDs.

A review of the extant literature, however, failed to detect experimental studies on occlusal rest structure and its fatigue resistance. The occlusal rest is an integral part of the RPD design. Its primary function is to provide vertical support for the denture. In doing so, it also serves to maintain stability of the denture, prevents impingement of the underlying mucosa, and distributes occlusal loads to the abutment teeth. Kratochvil $^{10}$ stated that the occlusal rests receive the greatest force produced in the mouth during function, and that the first consideration for these rests is rigidity, so that they do not flex under masticatory load. A rest that is too thin will deform elastically and fracture as a result of fatigue. Clinically, fatigue failures of the occlusal rests usually occur at the angle formed by the minor connector and the rest as it crosses the marginal ridge of the abutment tooth. ${ }^{11-14}$

Occasionally, the fracture occurs earlier than expected. The reasons often cited for this include the following: (1) the presence of a thin metal alloy because of insufficient rest seat preparation, ${ }^{10-12,14}(2)$ the presence of internal defects including porosity in the framework, ${ }^{11,12}$ and (3) accidental distortion. To provide the required rigidity and resistance to fracture, the occlusal rest should be 1.0 to $1.5 \mathrm{~mm}$ in thickness ${ }^{10-12,14}$ and $2.0 \mathrm{~mm}$ in width ${ }^{13}$ in the region where it crosses the marginal ridge of the abutment. This is made possible when an adequate rest seat is prepared on the abutment tooth. In spite of the guidelines for rest seat preparation, however, rest seats with depths less than $1.0 \mathrm{~mm}$ have been observed, as reported by Culwick. ${ }^{15}$ To date, the longevity or actual dimensions of the occlusal rests that have failed clinically have not been reported.

$\mathrm{Co}^{-} \mathrm{Cr}$ alloys have been widely used as a standard alloy for in vitro studies of RPD frameworks. ${ }^{6,8,9,16}$ However, there are insufficient reports on the performance of the $\mathrm{Ag}-\mathrm{Pd}-\mathrm{Cu}-\mathrm{Au}$ alloy. In Japan, this latter alloy is developed and used in place of gold alloys. Therefore, this study was conducted to evaluate the effect of heat treatment on the fatigue resistance and hardness of occlusal rests cast with the $\mathrm{Ag}-\mathrm{Pd}-\mathrm{Cu}^{-} \mathrm{Au}$ alloy. ${ }^{6,8,9,16}$
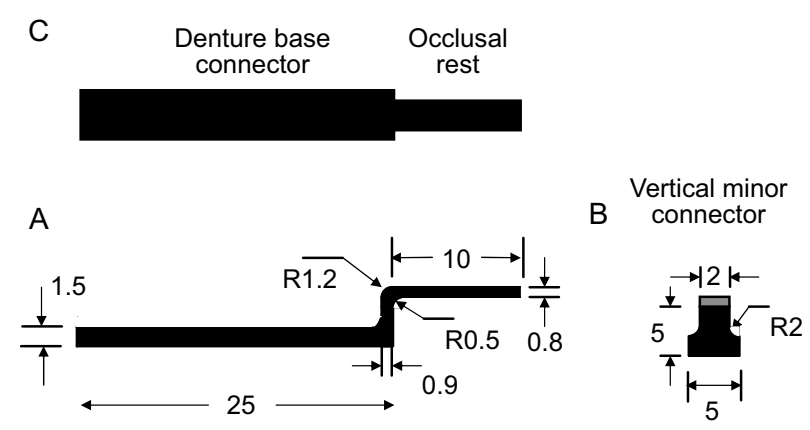

Fig. 1 Schematic illustration of a specimen: A, lateral view; $\mathrm{B}$, anterior view; $\mathrm{C}$, top view; and $\mathrm{r}$, radius (dimensions in $\mathrm{mm}$ ).

\section{Materials and methods}

\section{Specimen design}

An experimental structure was designed with 3 components: occlusal rest, vertical minor connector, and denture base connector (Fig. 1). From the designed structure, a master split mold was made with an industrial silicone material (KE1300T; Shin-Etsu Chemical, Tokyo, Japan). The wax patterns (Inlay Wax soft; Shofu Inc., Kyoto, Japan) were fabricated from the master mold.

\section{Casting method}

For a single set of specimens, 10 wax patterns were sprued at the center of a crucible former. The sprued wax patterns were placed in a casting ring and invested with a gypsum-bonded investment material (Cristobalite Investment $\mathrm{Mi}^{-}$ cro; GC Corp., Tokyo, Japan) (water/powder (W/P) ratio, 0.33). After setting of the investment, the ring was heated stepwise to 100,300 , and finally $700^{\circ} \mathrm{C}$ in an electric furnace for complete wax elimination. The respective temperatures were maintained for $1 \mathrm{~h}$.

The specimens were cast with fresh $\mathrm{Ag}$-Pd$\mathrm{Cu}-\mathrm{Au}$ alloy (Castwell MC; Lot No.0512051; GC Corp.) in a vacuum-pressure casting machine (CL-G; Heraeus Kulzer Japan, Tokyo, Japan). The melting temperature of the machine was set at $1080^{\circ} \mathrm{C}$. The cast structures were devested after bench cooling for $24 \mathrm{~h}$ and cleaned with a steam cleaner to remove the residual investment material.

The cast structures were pickled for $2 \mathrm{~min}$ in a palladium alloy cleaning solution (DentsplySankin Corp., Tokyo, Japan) heated at $60^{\circ} \mathrm{C}$, and then washed in tap water. Since stress concen- 
Table 1 Physical and mechanical properties of the $\mathrm{Ag}-\mathrm{Pd}-\mathrm{Cu}-\mathrm{Au}$ alloy tested.

\begin{tabular}{|c|c|c|c|c|c|c|}
\hline \multirow{2}{*}{ Melting point $\left({ }^{\circ} \mathrm{C}\right)$} & \multicolumn{2}{|c|}{ Hardness (HV) } & \multicolumn{2}{|c|}{ Tensile strength (MPa) } & \multicolumn{2}{|c|}{ Elongation (\%) } \\
\hline & $\mathrm{S}$ & $\mathrm{H}$ & $\mathrm{S}$ & $\mathrm{H}$ & $\mathrm{S}$ & $\mathrm{H}$ \\
\hline 930 & 146 & 280 & 500 & 804 & 28 & 3 \\
\hline
\end{tabular}

tration at an angle is markedly influenced by the degree of its curvature, the specimens were not polished so that any alteration in the angle formed by the inner curvature of the connector could be prevented. Specimens with defects such as micropores and metal protrusions, especially at the rest-vertical connector angle, were rejected and replaced. Incomplete and deformed castings were also discarded. Seventy-eight specimens were prepared in total and were divided equally into 3 groups.

According to the manufacturer, the test alloy contained (weight fraction) $46 \mathrm{wt} \% \mathrm{Ag}, 20 \mathrm{wt} \%$ $\mathrm{Pd}, 20 \mathrm{wt} \% \mathrm{Cu}, 12 \mathrm{wt} \% \mathrm{Au}$, and $2 \mathrm{wt} \%$ other metals. The physical and mechanical properties of the alloy specified by the manufacturer are listed in Table 1.

\section{Heat treatment method}

The following 3 methods were used for heat treatment.

\section{1) As-cast}

No heat treatment was applied to the specimens in this group ("as-cast" group).

\section{2) Heat treatment according to the manufacturer's instructions}

This treatment consisted of 2 procedures: the socalled softening treatment and hardening treatment. First, the cast specimens were heated in an electric furnace (LT II VPF; Jelenko CA, USA) to $700^{\circ} \mathrm{C}$, they were kept at this temperature for $5 \mathrm{~min}$ and then quenched into ice water. Subsequently, the specimens were left in the electric furnace at $400^{\circ} \mathrm{C}$ for $20 \mathrm{~min}$ and then bench cooled to the room temperature for $1 \mathrm{~h}$. This group will be denoted as the "manufacturer's instruction" group.

\section{3) Solution treatment at $800^{\circ} \mathrm{C}^{17}$}

The cast specimens were put in the furnace at room temperature, heated up to $800^{\circ} \mathrm{C}$, and kept at that temperature for $1 \mathrm{~h}$; then they were quenched into ice water. This group will be designated as the " $800^{\circ} \mathrm{C}$ solution treatment" group.

These heat treatments were carried out in the ambient atmosphere. The heating schedule was $35^{\circ} \mathrm{C} / \mathrm{min}$ from room temperature in both cases

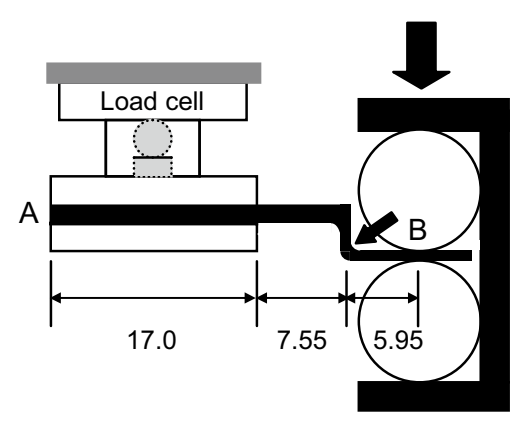

Fig. 2 Cantilever-type bending test of a specimen. The denture base connector component (A) was fixed with a jig connected to a load cell, and the occlusal rest component (B) was deflected downward as indicated by a thick arrow. Stress concentration occurred in the region indicated by a thin arrow (dimensions in $\mathrm{mm}$ ). The crosshead speed was 1 $\mathrm{mm} / \mathrm{min}$.

where heat treatment was applied. All heattreated specimens were again pickled in the same way as mentioned previously.

\section{Cantilever-type bending test}

To avoid immediate failure, the stress generated during function should be within the proportional limit of the component material; this condition is also required for a fatigue test. ${ }^{4,18}$

Accordingly, a cantilever-type bending test was preformed to determine the load or deflection to be applied to the fatigue test specimens. Six specimens were randomly selected from each group and tested using a universal testing machine (AG-1000E; Shimadzu Corp., Kyoto, Japan). The denture base connector component was gripped tightly by a jig connected to a load cell (Fig. 2). The occlusal rest component, held between 2 metal rollers, was deflected downward at a crosshead speed of $1 \mathrm{~mm} / \mathrm{min}$. The load generated was recorded till the proportional limit of the tested alloy was exceeded.

\section{Fatigue test}

A fatigue-testing machine (HR-1; Tokyo Testing Machine Inc., Tokyo, Japan) was used to test 20 specimens per group (Fig. 3). The machine was equipped with 4 metal rollers $10 \mathrm{~mm}$ in diameter for displacing downward the denture 

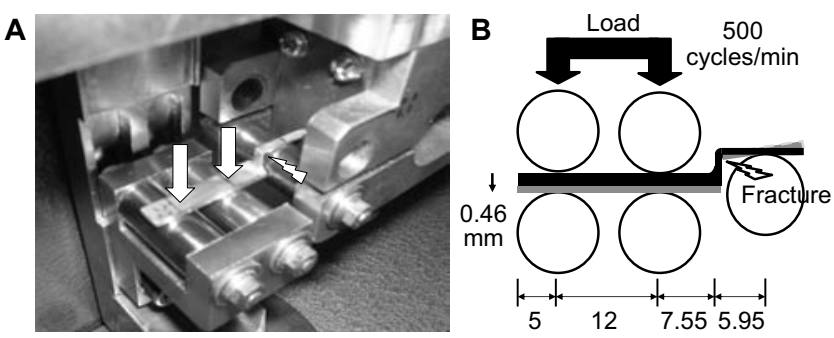

Fig. 3 A, specimen on a fatigue testing machine; $B$, schematic drawing of a specimen during the test. The occlusal rest component was supported by a single roller on the right side, while the denture base connector component placed between 4 rollers (opposing rollers not shown) was repeatedly displaced in the downward direction as shown by the block arrows on the left side. Stress concentration area is shown by a jagged arrow at the rest-vertical connector angle (dimensions in $\mathrm{mm}$ ).

base connector component, 1 roller for supporting the occlusal rest component, a dial gauge for setting the magnitude of displacement, and an automatic counter for recording the number of fatigue cycles. Although the part to be displaced was changed from the occlusal rest component to the base connector component, the positional relationship between the supporting and displacing components was exactly the same as that observed in the cantilever-type bending test.

The value of the denture base connector displacement, set using the dial gauge, was such that the deflection of the occlusal rest component would be $0.46 \mathrm{~mm}$ at the rest-vertical connector angle irrespective of the heat treatment group. The denture base connector was cyclically displaced at a frequency of 500 cycles/min, which produced a sinusoidal deflection of the occlusal rest until facture was detected by the testing machine or a preset limit of 2 million cycles was reached.

\section{Hardness test}

Rockwell B scale hardness (HRB) test (3 R Type, Imai Testing Machine Mfg., Saitama, Japan) was performed on the surface of the denture base connector component after fatigue testing. Twenty specimens per group were tested. The average value of 3 measurements obtained from each specimen was recorded.

\section{Statistics analysis}

With the measured values of fatigue and hardness tests, both dispersions did not reveal a normal distribution. Thus, the results for both the tests were expressed as medians. Further analy-

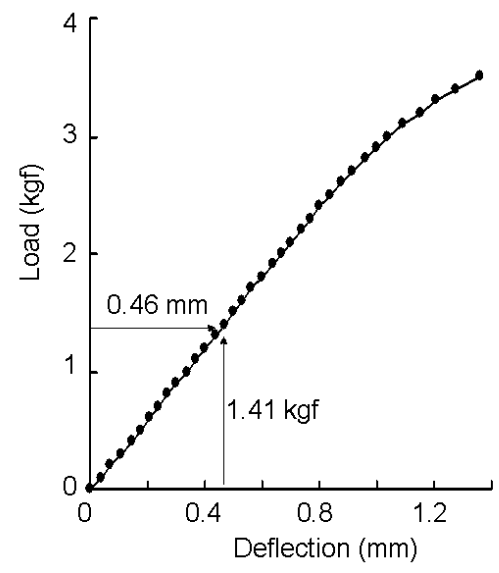

Fig. 4 A typical load-deflection curve obtained by a bending test. The cyclic deflection of the occlusal rest was determined to be $0.46 \mathrm{~mm}$ corresponding to a load of $1.41 \mathrm{kgf}$.

ses were conducted using the Kruskal-Wallis one-way analysis of variance (ANOVA) on ranks test, which was followed by the Dunn's multiple comparisons test.

\section{Results}

\section{Cantilever-type bending test}

Figure 4 shows a typical load-deflection curve obtained from the cantilever-type bending test. The curve shows that the proportional limit was reached at a deflection of approximately $0.9 \mathrm{~mm}$; an acceptable deflection of $0.5 \mathrm{~mm}$ for the fatigue test was determined from the curve, as discussed later. The loads that corresponded to the $0.5 \mathrm{~mm}$ deflection were recorded for each specimen and averaged for each heat treatment group. The ANOVA revealed no significant difference among the groups tested $(P=0.153)$. On average, a load of $1.41 \mathrm{kgf}$ corresponded to a deflection of 0.46 $\mathrm{mm}(1.53 \mathrm{kgf}$ to $0.5 \mathrm{~mm})$.

\section{Fatigue test}

The heat treatments significantly influenced the fatigue resistance $(P<0.003)$ (Table 2). By Dunn's multiple comparisons test, a significant difference $(P<0.05)$ was detected between the $800^{\circ} \mathrm{C}$ solution treatment and manufacturer's instruction groups. The $800^{\circ} \mathrm{C}$ solution treatment group demonstrated the best fatigue resistance.

\section{Hardness test}

The results of the Kruskal-Wallis ANOVA test revealed that the heat treatments significantly influenced the hardness $(P<0.001)$ (Table 3). Dunn's 
Table 2 Influences of heat treatment on fatigue resistance $\left(\right.$ count $\left.\times 10^{4}\right)$.

\begin{tabular}{llccccc}
\hline \multicolumn{1}{c}{ Group } & $\mathrm{N}$ & Median & & \multicolumn{2}{c}{$25 \%$} & \multicolumn{2}{c}{$75 \%$} \\
\hline As-cast & 20 & 8.17 & $7 \mathrm{~N}$ & 7 & 6.77 & 10.39 \\
Manufacturer's instruction & 20 & 7.12 & $\mathrm{NS}$ & 5.90 & 8.12 \\
$800^{\circ} \mathrm{C}$ Solution treatment & 20 & 9.64 & $*$ & 7.69 & 11.82 \\
\hline
\end{tabular}

Kruskal-Wallis one-way analysis of variance on ranks showed that the difference among the median values of the treatment groups was greater than that would be expected by chance alone $(P<0.003)$. The symbols * and NS represent "significant" $(P<0.05)$ and "nonsignificant", respectively (Dunn's multiple comparisons test). 25\% and $75 \%$ imply that $25 \%$ or $75 \%$ of the specimens demonstrated a lower value than the corresponding value.

Table 3 Influences of heat treatment on hardness (HRB).

\begin{tabular}{llccccc}
\hline \multicolumn{1}{c}{ Group } & $\mathrm{N}$ & Median & & $25 \%$ & $75 \%$ \\
\hline As-cast & 20 & 85.0 & $*$ & 7 & 81.0 & 86.0 \\
Manufacturer's instruction & 20 & 91.5 & $*$ \\
$800^{\circ} \mathrm{C}$ Solution treatment & 20 & 85.0 & $*$ & $\mathrm{NS}$ & 86.5 & 94.0 \\
\hline
\end{tabular}

Kruskal-Wallis one-way analysis of variance on ranks showed that the differences among the median values of the treatment groups was greater than those that would be expected by chance alone $(P<0.001)$. The symbols * and NS indicate "significant" $(P<0.05)$ and "nonsignificant", respectively (Dunn's multiple comparisons test). $25 \%$ and $75 \%$ mean that $25 \%$ or $75 \%$ of the specimens exhibited a lower value than the corresponding value.

multiple comparisons test showed a significant difference $(P<0.05)$ between the as-cast and manufacturer's instruction groups and also between the $800^{\circ} \mathrm{C}$ solution treatment and manufacturer's instruction groups. The highest hardness value was observed in the manufacturer's instruction group.

\section{Discussion}

The longevity of cast prostheses is an important concern for patients as well as dentists. In a previous study, the survival rate of $0.8 \mathrm{~mm}^{-}$ thick occlusal rests was estimated using fatigue test results. Considering the cumulative loading cycle during mastication $\left(2 \times 10^{5}\right.$ per year $),{ }^{19,20}$ the respective fatigue failure cycles were converted to number of years. The estimation was based anticipating that fracture would occur in $50 \%$ of the cast $\mathrm{Ag}-\mathrm{Pd}-\mathrm{Cu}-\mathrm{Au}$ alloy prostheses after 3 years. ${ }^{21}$ Therefore, the improvement in fatigue resistance would be one of the critical problems to be solved.

\section{Fatigue testing method}

The fracture position depends on the design of the RPD framework since fracture occurs in areas where stress concentration is high. Fatigue fracture of the occlusal rest begins with the initiation of microcracks at the corner formed by the union of the vertical minor connector and occlusal rest. Subsequent crack progression is also influenced by the occlusal rest thickness and a variety of defects present in the cast structure. In the present study, the $0.8 \mathrm{~mm}$-thickness of the occlusal rest was adopted with reference to the rest seat depths usually prepared by dentists. ${ }^{15}$ However, the length of the occlusal rest had to be extended to $10 \mathrm{~mm}$ so that the specimen could be properly supported in the fatigue testing machine. This issue will be discussed in detail later.

During mastication, forces are applied on the denture base area, which cause the RPD to move toward the underlying mucosa. The occlusal rest, which is placed on a relatively immobile abutment tooth, may flex while resisting the tissueward movement of the RPD, and thereby result in the creation of a high level of stress at the rest-vertical connector angle. The repeated occurrence of such stresses may eventually lead to the fatigue failure of the occlusal rest. In the present study, this clinical situation was simulated assuming a regulated tissueward displacement of the denture base connector component with respect to the immobile occlusal rest component (Fig. 3). Furthermore, 2 factors were taken into consideration: (1) the cyclic load/stress applied is within the proportional limit of the alloy, and (2) the maximum occlusal rest deflection or denture base connector displacement is within $0.5 \mathrm{~mm}$, which is comparable to the reported resiliency of 
the residual ridge tissue. ${ }^{22}$

According to the deflection theory of cantilevered structures, the flexural rigidity of a bar is directly proportional to its width and the cube of its thickness; however, it is inversely proportional to the cube of its length. ${ }^{16}$ Correspondingly, these values were $2.0,0.8$, and $5.95 \mathrm{~mm}$ for the occlusal rest component and 5.0, 1.5, and 7.55 $\mathrm{mm}$ for the denture base connector component, respectively (Figs. 1 and 2). The flexural rigidity of the latter component was estimated to be 8.07 times that of the former. Therefore, it was as sumed that the recorded curve reflected the loaddeflection behavior of the less rigid occlusal rest component (Fig. 4). Hence, considering the loaddeflection relationship, the displacement of the denture base connector was set so that the deflection of the occlusal rest component would be 0.46 $\mathrm{mm}$ corresponding to a load of $1.41 \mathrm{kgf}$.

This load magnitude, i.e., $1.41 \mathrm{kgf}$, is small compared with the reported average masticatory force $(11.73 \mathrm{kgf})^{4}$ directed to the RPD during chewing. In this study, however, the occlusal rest was supported far $(5.95 \mathrm{~mm})$ from the inner surface of the vertical connector component, which resulted in the relatively decreased resistance of the occlusal rest to the applied load. A hypothetical calculation based on the abovementioned deflection theory suggested that repositioning of the support closer to the vertical connector by half the distance would result in an 8-fold increase in the stiffness of the occlusal rest component. Consequently, the load required to obtain the same displacement would also increase 8 times, which is comparable to the reported average masticatory force applied on the RPD. Therefore, it is assumed that the bending moment (product of the load and cantilever arm length) or bending stress generated at the rest-vertical connector angle might be almost comparable to that generated in vivo.

Increased loading frequency slightly improves the fatigue resistance of materials. ${ }^{23}$ However, it has been observed that significant effects appear only when the frequency is increased to 10 $\mathrm{Hz}$ or higher. ${ }^{19,20}$ The frequency of 500 cycles/min $(8.3 \mathrm{~Hz})$ used in this study is higher than the reported chewing frequency ( 1 to $2 \mathrm{~Hz}) ;^{3}$ however, it is considerably lower when compared with the frequencies used in other studies ${ }^{24}$ and is even within the minimum range. Therefore, it is assumed that the effect of the frequency utilized in this study might be comparable to that in vivo.

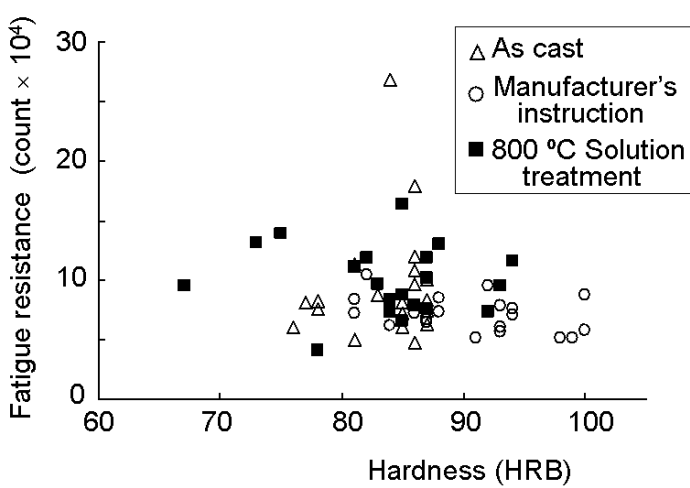

Fig. 5 Relationship between hardness and fatigue resistance. No obvious correlation was observed between hardness and fatigue strength (correlation coefficient, 0.21). A slight reverse relation was observed.

The denture base connector component of each specimen was gripped tightly by 2 pairs of rollers in the fatigue test. In vivo, this part will rotate on the supporting tissues when occlusal force is applied. Hence, there is a possibility that the number of occurrences of the fatigue destruction of the rests was underestimated. In vivo, the life of the occlusal rests may be more prolonged than that estimated from the results of this experiment.

\section{Fatigue strength and hardness}

Contrary to expectations, no obvious relationship was found between the hardness and fatigue resistance (correlation coefficient, 0.21) (Fig. 5). Rather, a slight tendency for reverse relation was observed in the scatter diagram.

Using the conversion table provided by the manufacturer of the hardness tester, the median hardness value (91.5 HRB) of the manufacturer's instruction group was converted to $200 \mathrm{HV}$ (Vickers hardness). This value, although approximately $71.4 \%$ of the value ( $280 \mathrm{HV})$ specified by the manufacturer, corresponds roughly with those reported by Nakamura ${ }^{25}$ and Yamatoya et $\mathrm{al}^{26}$ and are presumably at the level expected from the heat treatment.

Fukui et $\mathrm{al}^{17}$ have studied heat treatments of $\mathrm{Ag}-\mathrm{Pd}-\mathrm{Cu}$ wrought alloy containing $12 \mathrm{wt} \% \mathrm{Au}$. According to them, the alloys were hardened and strengthened without reduction in ductility when quenched in ice water from $800 \sim 850^{\circ} \mathrm{C}$, and that the attained hardness depended sensitively on the treatment temperature range above $800^{\circ} \mathrm{C}$. Furthermore, they proposed a hypothesis that the lattice strain appearing near the $\alpha$-solid 
solubility limit was responsible for the solution hardening. On the other hand, the age-hardening treatment at temperatures around 400 ${ }^{\circ} \mathrm{C}$ decreased the ductility; however, the tensile strength and hardness were the same as those obtained by the solution treatment. It should be noted that the solution-treated alloy showed 1.8 times greater fatigue limit than the agehardened alloy. Similarly, in the present study, the $800^{\circ} \mathrm{C}$ solution treatment group showed the highest fatigue resistance. However, the hardness of the as-cast and $800^{\circ} \mathrm{C}$ solution treatment groups showed the same value, i.e., 85.0 HRB, which did not necessarily agree with the tendencies reported by Fukui et al. ${ }^{17}$ In another study, Fukui et $\mathrm{al}^{27}$ reported a difference in the hardening behavior of cast and wrought specimens; this difference may account for the unexpected low hardness of the $800^{\circ} \mathrm{C}$ solution treatment group observed.

Nakamura ${ }^{25}$ reported that the heat treatment applied according to the manufacturer's instructions improved the hardness and tensile strength but did not improve the fatigue strength. Although a tensile test was not conducted, the present results roughly agreed with his results pertaining to fatigue strength and hardness.

By analyzing the results from the literature review in conjunction with those from the present study, it can be concluded that the $800^{\circ} \mathrm{C}$ solution treatment could improve not only the fatigue resistance of $\mathrm{Ag}-\mathrm{Pd}-\mathrm{Cu}-\mathrm{Au}$ alloys but also other mechanical properties, including tensile strength, ductility, and toughness.

In this study, the fatigue resistance of a 0.8 mm-thick occlusal rest was evaluated under controlled and specific conditions that did not completely reflect in vivo situations. For instance, the specimens were tested in a dry environment. Clinically, an RPD bathed in saliva is in contact with different substances that may lead to corrosion fatigue. Further investigation should be conducted to comprehend how defects inherent in cast alloys affect the fatigue behavior. However, in spite of certain limitations, this study may help dentists and dental technicians choose the heat treatment condition that is most suitable for RPD rests.

\section{Conclusion}

The influences of 3 heat treatment methods on the fatigue strength and hardness of a cast $\mathrm{Ag}^{-}$ $\mathrm{Pd}-\mathrm{Cu}$-alloy containing $12 \mathrm{wt} \% \mathrm{Au}$ were investigated. Within the range of the present results, the following conclusions were made.

The heat treatments significantly influenced the fatigue resistance $(P<0.003)$ and hardness $(P<0.001)$. With regard to fatigue resistance, a significant difference $(P<0.05)$ was detected between the $800^{\circ} \mathrm{C}$ solution treatment $\left(9.64 \times 10^{4}\right)$ and manufacturer's instruction groups $(7.12 \times$ $\left.10^{4}\right)$. With respect to hardness, a significant difference $(P<0.05)$ was observed between the ascast (HRB, 85.0) and manufacturer's instruction groups (HRB, 91.5) and also between the $800^{\circ} \mathrm{C}$ solution treatment (HRB, 85.0) and manufacturer's instruction groups.

To avoid the fatigue fracture of cast $\mathrm{Ag}-\mathrm{Pd}-\mathrm{Cu}^{-}$ $\mathrm{Au}$ alloy RPDs, the $800^{\circ} \mathrm{C}$ solution treatment is recommended. Heat treatment according to the manufacturer's instructions did not possess significant advantages.

Acknowledgments: This study was technologically supported by the Division of Biomaterial Science, Department of Oral Health Science, Course for Oral Life Science, Niigata University Graduate School of Medical and Dental Sciences. Particularly, the authors thank Dr. Seigo Okawa and Mr. Syuji Nakano of the Division for their kind advice and help.

\section{References}

1. Lewis AJ. Failure of removable partial denture castings during service. J Prosthet Dent 39: 147-149, 1978.

2. Vermeulen AH, Keltjens HM, van't Hof MA et al. Ten-year evaluation of removable partial dentures: survival rates based on retreatment, not wearing and replacement. J Prosthet Dent 76: 267-272, 1996.

3. Bates JF, Stafford GD, Harrison A. Masticatory function-a review of the literature. (II) Speed of movement of mandible, rate of chewing and forces developed in chewing. J Oral Rehabil 2: 349-361, 1975.

4. Craig RG, Powers JM. Restorative dental material, 11th ed. 68-91 St. Louis: Mosby, 2001.

5. Matheson GR, Brudvik JS, Nicholls JI. Behavior of wrought wire clasps after repeated permanent deformation. J Prosthet Dent 55: 226-231, 1986.

6. Vallittu PK, Kokkonen M. Deflection fatigue of 
cobalt-chromium, titanium, and gold alloy cast denture clasp. J Prosthet Dent 74: 412-419, 1995.

7. Vallittu PK. Fatigue resistance and stress of wrought-steel wire clasps. J Prosthodont 5: 186-192, 1996.

8. Ben-Ur Z, Matalon S, Aviv I et al. Rigidity of major connectors when subjected to bending and torsion forces. J Prosthet Dent 62: 557-562, 1989.

9. Ohkubo C, Abe M, Miyata T et al. Comparative strengths of metal framework structures for removable partial dentures. J Prosthet Dent 78: 302-308, 1997.

10. Kratochvil FJ. Partial removable prosthodontics, 11-21, Philadelphia: W. B. Saunders, 1988.

11. Kazanoglu A, Smith EH. Replacement technique for a broken occlusal rest. J Prosthet Dent 48: 621-623, 1982.

12. Ben-Ur Z, Patael H, Cardash HS et al. The fracture of cobalt-chromium alloy removable partial dentures. Quintessence Int 17: 797-801, 1986.

13. Jones RM, Goodacre CJ, Brown DT. Dentin exposure and decay incidence when removable partial denture rest seats are prepared in tooth structure. Int J Prosthodont 5: 227-236, 1992.

14. McGlvney GP, Carr A, McCracken WL. McCracken's removable partial prosthodontics, 10th ed. 77-91, St. Louis: Mosby, 1999.

15. Culwick PF, Howell PG, Faigenblum MJ. The size of occlusal rest seats prepared for removable partial dentures. Br Dent J 189: 318-322, 2000.

16. Bates JF. The mechanical properties of the cobaltchromium alloys and their relation to partial denture design. Br Dent J 119: 389-396, 1965.

17. Fukui H, Sinoda S, Mukai M. Effect of Heat Treatment on Mechanical Properties of Type IV Gold and 12wt\% Au-Pd-Ag Alloys. Dent Mater J 11:
141-148, 1992.

18. Stewart RB, Desjardins RP, Laney WR et al. Fatigue strength of cantilevered metal frameworks for tissue-integrated prostheses. J Prosthet Dent 68: 83-92, 1992.

19. Wiskott HW, Nicholls JI, Belser UC. Fatigue resistance of soldered joints: a methodological study. Dent Mater 10: 215-220, 1994.

20. Wiskott HW, Nicholls JI, Belser UC. Stress fatigue: basic principles and prosthodontic implications. Int J Prosthodont 8: 105-116, 1995.

21. Gapido CG, Kobayashi H, Miyakawa O et al. Fatigue resistance of cast occlusal rests using $\mathrm{Co}^{-}$ $\mathrm{Cr}$ and $\mathrm{Ag}-\mathrm{Pd}-\mathrm{Cu}-\mathrm{Au}$ alloys. J Prosthet Dent 90: 261-269, 2003.

22. Monteith BD. Management of loading forces on mandibular distal-extension prostheses. Part 1: Evaluation of concepts for design. J Prosthet dent, 52: 673-681, 1984.

23. American Society for Metals. Metals Handbook Vol. 8. 9th ed. 363-435. Ohio: American Society for Metals, 1985.

24. Kato H. Fatigue properties of dental alloys $12 \%$ $\mathrm{Au}-\mathrm{Pd}-\mathrm{Ag}$ alloy and type III gold alloy. Aichi Gakuin Daigaku Shigakkai Shi 27: 1017-1027, 1989.

25. Nakamura H. Effects of heat treatment on fatigue strength of cast gold-silver-palladium alloy. Dent Mater J 16: 141-154, 1997.

26. Yamatoya F, Nakamura K, Goto S. Effects of gold addition for the properties of casting $\mathrm{Pd}-\mathrm{Cu}-\mathrm{Ag}$ alloy. Dent Mater J 4: 730-753, 1985.

27. Fukui H, Mukai M, Sinoda S. Strengthening mechanism of $\mathrm{Au}-\mathrm{Pd}-\mathrm{Ag}-\mathrm{Cu}$ system. Dent Mater J 12: 685-690, 1993. 